\title{
Optimizing prefabricated construction techniques in UAE as a solution to shortage of middle-income housing
}

\author{
Mohamed Elkaftangui ${ }^{1}$, Basem Mohamed $^{1}$ \\ ${ }^{1}$ Abu Dhabi University, Architectural Department, P.o.Box 59911, Abu Dhabi University, United Arab Emirates
}

\begin{abstract}
Housing is a major subject in the Middle East and North Africa (MENA) region, JLL, the world's leading real estate investment and advisory firm, highlights the social and economic impact of a marked shortfall in the required supply of middle-income housing, suggesting that significant efforts are needed to address the current imbalance. For an equal standard and life style in UAE and KSA, the gap of sale and rent prices raises many questions. The middle-income sector of the market represent almost 40 percent of all households in the UAE. Several factors that have contributed to the current shortage of affordable housing, high land values, High capital costs for associated infrastructure development, low adoption of prefabricated construction techniques have contributed to higher construction costs, lower financial returns, making such developments less attractive for developers, limited access to suitable finance for low income families, due to generally immature mortgage markets. Resolving the shortage of middle-income housing requires a concentrated effort involving government agencies, private developers and other stakeholders. This Study will investigate the UAE Housing market to propose solutions for a better progress of the precast sector and focusing on the promotion of sustainable and industrial approaches to construction.
\end{abstract}

\section{Introduction}

The United Arab Emirates (UAE) faces a current estimated demand from 390,000 low income Emirati households [1]. The importance of the middle-income sector of the market should not be under estimated, with over 820,000 middle-income households, representing almost 40 percent of all households in the UAE. Only 22 percent of residential units launched in 2016 to date in Dubai are "affordable" to "middle-income" households while we have not seen any residential units being launched this year that meet the meaning of 'affordable'.

The UAE Vision 2021 articulates the importance of family and community. The vision articulates the importance of protecting the environment, preserving culture, providing access to infrastructure and facilities to create well rounded lives for Nationals. Efforts were intensified in 2010 through the Emirati Family Housing Program to create 'complete communities' of over 13,000 villas with regard to the above requirements within four years [2].

Many programs and initiatives have been proposed to meet the demand, in 2014, the leader developer of Abu Dhabi, Aldar has delivered to the Government of Abu Dhabi, 4,857 villas at Al Falah, bringing the total number of units developed or delivered to 6,744 homes for UAE nationals.

In the same year, other 1,887 units have been delivered to the Abu Dhabi Government authorities, these developments consist of 839 villas in Watani and Al
Raha in Abu Dhabi, 448 villas at Sila'a in the Western Region, and 600 villas at Ghuraibah in Al Ain.

Another development by Abu Dhabi-governmentowned builder Aldar, launched on 2017, consists of 1,020 villas on Yas Island and 996 villas in Al Falah and 275 Villas at $\mathrm{Al}$ Ghuraibah in $\mathrm{Al}$ Ain.

In August 2015, and according to Dubai Municipality's director, two communities have been announced, consisting of 1,400 and 1,000 villas, for nationals in Wadi Safa and Al Aweer 1, and the distribution of land to eligible citizens in Wadi Safa. In November 2017, the Abu Dhabi government has announced a new housing project, called Al Riyadh City, as part of the capital's drive to expand public housing policies, The project, said to be Abu Dhabi's largest ever housing development, is expected to lodge 200,000 UAE citizens and occupy $45 \%$ of the city's total residential land area.

These projects have a total developmental value of Dhs 5.7bn and are being fully funded by the Abu Dhabi government, the developer said in a statement. The UAE, like other Gulf Arab countries, spends a large amount on social welfare for its citizens. Providing free or low cost housing to Emiratis is one of the welfare measures widely adopted by the state.

The Emirates Development Bank (EDB), which was launched with Dh10 billion authorised capital, is set to spearhead the development of affordable homes with a commitment to deliver 30,000 homes for the UAE citizens from 2015 to 2021. 
The huge existence of a precast concrete industry and the numerous successful building projects achieved using precast concrete, for the whole or just a part of the structure, is proof that the technique is practical and economical, and certainly present the best solution to meet the expectations of UAE vision 2021 for fast housing deliverable in term of quantity and quality.

In this research, we highlight the reality of the supply and demand of the UAE residential sector and analyse what actions has been undertaken by the UAE government to meet the growing demand of housing units, we also analyst the practice of the precast concrete activity in UAE to enhance the mechanism of development of the precast concrete

\section{Precast construction in UAE}

Precast concrete comprises roughly 30 per cent of the UAE construction market and its share is increasing, the competition for precast is from ready-mix, steel structures and building blocks.

According to the statement of the Abu Dhabi Chamber of Commerce and Industry, the UAE now has a huge, advanced infrastructure in precast, sophisticated factories using the latest technologies in production lines. The total value of the precast concrete market has been valued at around $\$ 1.6 \mathrm{bn}$, there are over 25,000 labourers and technicians working in the precast industry in the UAE in at least 29 precast manufacturing facilities, with the construction cost of each of these factories ranging from $\$ 50 \mathrm{~m}$ to $\$ 350 \mathrm{~m}$.

Prefabrication has been proven to provide up to $52 \%$ savings in the global construction waste. The global movement for the reduction of carbon emission in the construction industries of the world is geared towards the creation of environmentally responsible building technologies. Several studies propagate prefabrication techniques and usage of precast concrete elements in construction, as a significant contributor to positive environmental and economic impacts especially in highly commercialised regions like the UAE.

Using precast concrete offers many general advantages as high loading capacity, longer span for slab and beams, less formwork but we emphases the following specific advantages in relation with UAE context:

- Faster construction time: $80-90 \%$ of the recent repetitive massive housing projects in the UAE are made of precast concrete as an efficient alternative to the traditional building techniques, according to Gulf Precast leader of the precast concrete manufacturers in UAE, a regular medium size development of 650 villas $500 \mathrm{~m} 2$ each (example mentioned is: Akoya and Akoya oxygen villas in Dubai), required a total duration of 6 months for engineering, assembly and the final delivery. On the $\mathrm{Al}$ Falah villa development in Abu Dhabi, 4,126 villas were completed in 24 months using precast, while only 730 villas were completed in 20 month using traditional caston-site.

- Cost reduction: comparison is based on the scale of the development; for small scale projects it would reach up to $2 \mathrm{x}$ the traditional construction technique. While, in repetitive, big scale developments the price can reach the same price of the traditional construction techniques with the time benefit in both cases. The use of modular components with precast superstructures and the incorporation of a pre-fabricated bathroom pod installed at the precast erection stage illustrates a clear time saving of approximately 8 programme days per villa, a significant advantage of early completion of bathroom units is a reduced dependence of bathroom MEP final-fix installations and associated testing \& commissioning inspections on ceramic tiling completion [3].

- Better quality and more durable products: the precast concrete industry offers an extraordinarily diverse range of unique and creative building technologies, which enables the manufacturers globally develop initiative building and infrastructure products to architects [4]. The UAE manufactures produces mainly holowcore slabs, beams and columns, wall panels with a maximum standard of $4.7 \mathrm{~m}$. / $8.5 \mathrm{~m}$. Due to crane capacities, table size and transport, GRC and GRG. The precast concrete offers the possibility to have less weather dependency and to maintain the high precast concrete quality, the UAE hot and humid climate does not always work in favour of site-cast concrete.

- Sustainable: made of natural raw materials (stones, gravels, sand, cement), locally available almost everywhere in UAE, precast concrete minimizes the whole life cycle impact on the environment when compared with other construction materials. Precast concrete meet the requirement of Estidama rating system [5] which is the UAE version of the LEED, with a minimum mandatory U Value of 0.4 in Dubai and 0.32 in Abu Dhabi.

\section{Defining failures in the practice of the precast concrete activity from design to construction}

The practice of the precast concrete activity in UAE meets some difficulties during the execution of super projects. These problems are mainly generated during the phases of the design and the construction which affect the quality of final product or delivery time.

There are two methods of housing provision for Nationals in the Emirate of Abu Dhabi, who may choose between the following options:

- Land and loan: Eligible Nationals will be provided with a plot of land and financing to build a house. 'Bayti' (My Home) initiative for Abu Dhabi citizens, which was developed to ease the burden on Abu Dhabi Emirati families utilising Abu Dhabi Housing Authority housing loans, provides 58 structurally and architecturally preapproved housing designs. The number of rooms ranges between 4 and 8 bedrooms, with the possibility of future expansion. It streamlines the process of delivering housing to the required quality, on time and on budget. The initiative has also shortened build time, with full construction to be completed within a maximum period of two years. The expected cost, and interest-free loan amount, for each house is AED 2 million. This initiative and mean of delivery are not part of the precast concrete 
activity but generally cast in site and considered as an individual construction.

- Allocation: The government provides eligible Nationals a house that is fully constructed and serviced by all relevant infrastructure and utilities. Houses are likely built by a master planner/master developer, this mass construction where thousands of houses to be delivered through different governmental programs as mentioned in the introduction.

In this research, we select the most important project "Al Falah" delivered recently in Abu Dhabi and highlight and analyse some facts relevant to the execution of this type of projects and the precast activity 'Figure 1', 'Figure 2'.

Al Falah Community development in Abu Dhabi consists of five 'villages' presenting 4,857 villas and a range of community amenities, providing sustainable neighbourhoods serving modern needs and lifestyles whist preserving and promoting the traditional Emirati identity and preferred style of living.

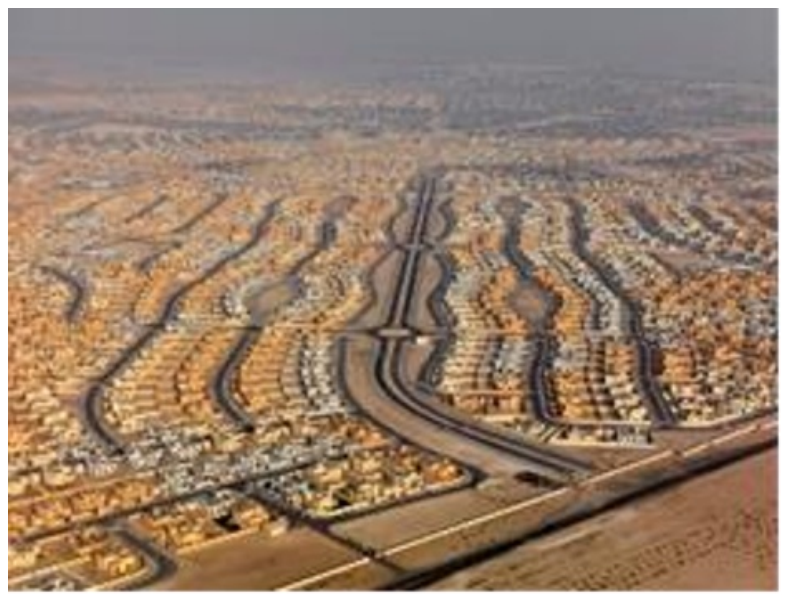

Figure 1. Site Aerial view of Al-Falah housing project.

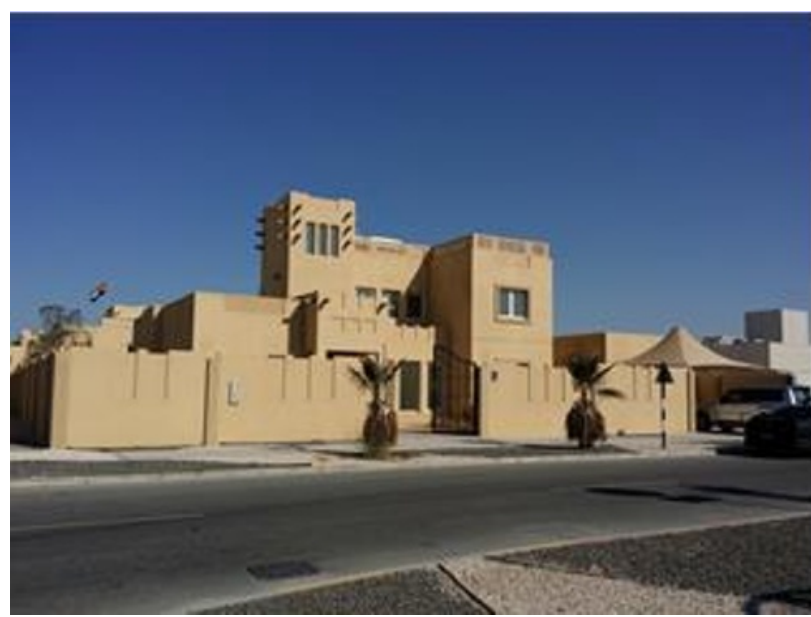

Figure 2. One of the precast concrete family houses in Al-Falah development

\subsection{Design and Users}

Although the government's commitment large effort to improve Emirati housing, "Abu Dhabi Municipality- permit Department" registered in 2016 a total number of 8,769 permits of modifications and addition permits in Emirati housing in Abu Dhabi, presenting 2181 addition and 5737 modification permits. In $\mathrm{Al}$ Falah new community of 4869 houses the number of modifications and addition permits in (2014-2015-2016) is (3272) permits presenting $67.2 \%$ of the houses.

According to the owners and the permits contents [6], the majorities of modifications could be summarized as follow:

- Modification of double height entrance Lobby, as it seem to be generally not preferable.

- The location of ground water tank and pump room is contradicting with landscape layout.

- The location of fire hydrants are not coordinated with villas Main gate/entry.

- The main gate is not providing enough the privacy required in Emirati house.

- The French window is not a suitable design for Emirati.

- The colour and arrangement of toilets and ceramic cladding are not suitable.

- Tight space between the driver's room and the fence is really tight and need to be relocated.

- Living rooms is too small.

- Water, electricity and HVAC need monitoring neglected according to water and electricity bills.

\subsection{Construction and Management}

In Al-Falah project, the critical challenge has been to constantly build five villas per day by using precast fabrications to reduce labor costs by up to $25 \%$, compared to conventional concrete. The following critical areas for the delivery solutions applied by El-Seif Engineering Contracting for the Construction of 2,069 Villas across two villages of the Al Falah development are highlighted below:

- Co-ordination conflicts: particularly where milestone completion dates are combined and shared access required at multiple phases; from concurrent villaerection vs. deep drainage, to wearing course asphalting vs. villa finishes, snagging and handover, amongst others. - Many conflicts appeared as a result of variable terrain levels and required interconnections between villa and infrastructure-contractor constructed drainage components.

\section{Reflexions and Conclusion}

A range of factors influence the success of the precast concrete activity and the construction of big scale fast track projects. Attention for design and construction must escape failures listed above and maximize the advantages that the precast concrete construction may offer. The design must be based on an understanding and response to cultural factors relevant to national housing, this include privacy, family size average between $7-10$ people, family expansion.

Environmental factors influence the National housing by their physical environment including the landscape variety, different climates and regions. These 
considerations and the early stage involvement of the future owners of tenants must definitely reduce the permits modifications.

Use of universally accessible Building Information Modelling (BIM) technology can resolve co-ordination conflicts presented above, using software like Revit or Tekla allow all architectural, structural and electromechanical design processes occur at the same time since 'modules' are parts of an entire building. Buildings are virtually tested, enabling asset managers to evaluate building performance prior to manufacturing and construction. The built BIM model can be combined with Facility Management (FM) software enabling all project teams manage and control the assets.

A 'cloud-based', 3D modelling service would likely facilitate more timely review of design modifications for such conflicts and perhaps eliminate many on-site if combined into an Early-Contractor-Involvement (ECI) design environment. A real time model visualization would allow for more immediate design and construction-phase planning and decision making by all stakeholders.

Modular bathroom units were not exploited on the $\mathrm{Al}$ Falah project, although they offer considerable advantages and savings of approximately 8 programme days per villa in time delivery, quality constancy and minimal materials wastage [3].

Given the climatic conditions in the UAE, the need for a shading devises can be considered inevitable. An approach for the design of a shading systems stems from the plasticity of concrete as a material, and supported by a computational strategy with specific focus on opening size in relation to allocated function must be undertaken to develop the actual precast wall panels used in UAE whish neglect the opening treatments and the opening protection [7], this process must be initiated with a series of assumptions derived from examining residential design trends in the UAE, with specific focus on opening size in relation to allocated function. Providing the possibility to

Modularity and Flexibility of the precast concrete construction provides adaptability to keep costs down, the development of this construction method permits for basic shapes to be combined in multiple ways that allow precast systems to be pre-built.

An exploration work with the ambitions of rethinking the design and production of precast concrete façade panels focusing on the UAE Industry is required to design and optimize an integrated facade system generating a self-shading element in response to specific contextual conditions comprising the optimization of window extrusion and rotation to find the adequate solution [8].
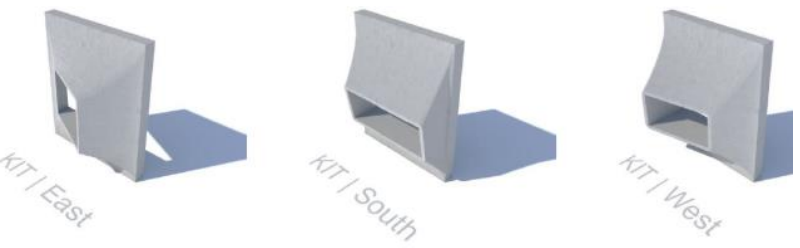

Figure 3. Wall Panels Taxonomy
This optimization can follow cardinal orientations; East, South East, South, South West, and West, Resulted in a catalogue of 30 variations of optimized panels, corresponding to all possible locations, functions and orientations.

The role of digital fabrication in the form of 3D printing could be anticipated, recently, advancements in Additive Manufacturing techniques, such 3-Dimentional printing have been a vital area of exploration since its development in the mid-1990s. We believe that 3D printing of concrete allows for producing highly customized building components and could create a new era in the construction industry when adapted to specific contextual and cultural environments.

All stakeholders need to be educated on the importance and benefits of precast concrete construction. Builders most likely will be interested in initial costs, time savings, construction methods, reduced job site impact and planning. Owners most likely will be more interested in long-term value, design flexibility, life cycle costs, safety and initial costs.

Modular solutions, new precast technologies are well appropriate to low and midrise residential developments from townhouses and villas to apartment buildings and communities. The efficient use of precast along with the suitable building methodologies and technologies allows for the efficacious delivery, in affordable stages, in a fraction of the conventional construction cost and time.

\section{References}

1. J. Gavin, J. Lasalle, jll's Year in Review report for UAE - JLL MENA, (2017). http://www.jllmena.com/mena/en-gb/research/397/j1l-2017-yearin-review-report-for-uae

2. https://government.ae/en/about-the-uae/theuae.../the-federal-national-council-

3. J. Eyre, R. Hart, G. Connolly. Optimising delivery solutions for social \& affordable housing, Abu Dhabi, UAE. Al Falah Community Project, a social housing case study (2004). Available on (www.conference.net.au/cibwbc13/papers/cibwbc20 13 submission 35.pdf)

4. S. Kumar, "Precast Take the Lead". (2011). Available from $<$ http://www.constructionweekonline.com/article17403-precast-takes-the-lead/> (accessed 13 Feb. 2018).

5. https://www.upc.gov.ae/en/publications/...guidelines/ pearl-rating-manual-estidama

6. Abu Dhabi Municipality, Permit Department. https://www.abudhabi.ae/portal/public/en/department s/adm

7. B. Bell, "Topocast, Parametric Precast". Available from <http://topocastlab.com/portfolio/parametricprecast/> (accessed 7 Feb. 2018).

8. B. Mohamed, M. Elkaftangui, R. Zureikat. "Towards Rethinking the Precast Concrete Industry in the UAE", Learning prototyping and Adapting, CADRIA 2018, pp287-296. 